\title{
COMPARISON OF THE EFFECT OF INTRATHECAL 0.5 \% ISOBARIC BUPIVACAINE AND 0.5\% ISOBARIC LEVOBUPIVACAINE IN PATIENTS UNDERGOING LOWER ABDOMINAL AND LOWER LIMB SURGERIES
}

\author{
Priya Mattoo', Ashok Chowdhary², Nandita Mehta ${ }^{3}$, Vanilla Chopra ${ }^{4}$ \\ ${ }_{13}^{\text {rd }}$ Year Postgraduate, Department of Anaesthesia, Acharya Shri Chander College of Medical Sciences and Hospital, Jammu. \\ ${ }^{2}$ Associate Professor, Department of Anaesthesia and Intensive Care, Acharya Shri Chander College of Medical Sciences and Hospital. \\ 3 Professor and HOD, Department of Anaesthesia and Intensive Care, Acharya Shri Chander College of Medical Sciences and Hospital. \\ ${ }_{4}^{4}$ Assistant Professor, Department of Anaesthesia and Intensive Care, Acharya Shri Chander College of Medical Sciences and Hospital.
}

\section{ABSTRACT}

\section{BACKGROUND AND OBJECTIVES}

Levobupivacaine, a new local anaesthetic, has been recently introduced into clinical practice because of its lower toxic effects for heart and central nervous system. It has been already investigated in epidural and local-regional techniques, but more has to be known regarding its characteristics in spinal anaesthesia. The aim of our study was to compare clinical and anaesthetic features of levobupivacaine and isobaric bupivacaine when intrathecally administered in 100 patients undergoing lower abdominal and lower limb surgeries.

\section{METHODS}

$2.5 \mathrm{~mL}$ of glucose-free levobupivacaine $0.5 \%$ (Group L) or $2.5 \mathrm{~mL}$ of isobaric bupivacaine $0.5 \%$ (Group B) was administered in 50 patients each. Sensory and motor blockade evaluated by the pinprick test and a modified Bromage score respectively. Vital parameters, intraoperative VAS were recorded as well.

\section{RESULTS}

No statistically significant differences between groups were observed in either anaesthetic potencies. Nevertheless, spinal puncture was accompanied by hypotension in 3 patients and bradycardia in 2 patients of group B, and hypotension in 6 patients and bradycardia in 3 patients in group L. In both cases, haemodynamics were promptly and successfully treated, with no sequelae.

\section{CONCLUSION}

In conclusion, levobupivacaine although has no added advantage over isobaric bupivacaine but having lesser CNS and cardiac effects after accidental intravascular injection, is an interesting alternative to bupivacaine for spinal anaesthesia in lower abdominal and lower limb surgeries.

\section{KEYWORDS}

Levobupivacaine, Bupivacaine, Isobaric.

HOW TO CITE THIS ARTICLE: Mattoo P, Chowdhary A, Mehta N, et al. Comparison of the effect of Intrathecal $0.5 \%$ isobaric bupivacaine and $0.5 \%$ isobaric levobupivacaine in patients undergoing lower abdominal and lower limb surgeries. J. Evolution Med. Dent. Sci. 2016;5(77):5668-5672, DOI: 10.14260/jemds/2016/1279

\section{INTRODUCTION}

Adequate analgesia is the hallmark and basic requirement of every anaesthetic technique. Failure to relieve pain is morally and ethically unacceptable and adequate pain relief can be considered a basic human right. Post-operative pain management can improve functionality and reduce physiological and psychological morbidity and in turn hospital stay and also improve quality of life (Farquhar et al, 2008). ${ }^{1}$ Regional anaesthesia has been a boon to anaesthesiologists in the last few decades.

It avoids many of the serious problems of general anaesthesia as well as provides near optimal conditions for surgery. Once administered regional anaesthesia provides an unvarying dense analgesia unlike GA, where both the sedation

Financial or Other, Competing Interest: None.

Submission 26-04-2016, Peer Review 11-09-2016,

Acceptance 17-09-2016, Published 23-09-2016.

Corresponding Author:

Dr. Priya Mattoo,

H. No. 544, Lane No. 8 ,

Hazuri Bagh, P/o. Talab Tillo Bohri,

Jammu-180002, Jammu \& Kashmir.

E-mail: drpriyamattoo87@gmail.com

DOI: $10.14260 /$ jemds/2016/1279 and the analgesia are dynamic, keep varying and require constant manipulations (Timothy R Lubenoe et al, 2006). ${ }^{2}$ There is very little interference with the homeostasis and milieu except for the early remediable hypotension of central neuraxial blockade.

Leonard Corning, a neurologist in New York, performed the first spinal anaesthesia in 1885 (Douglas Bason et al 1885). ${ }^{3}$ He was experimenting with cocaine on the spinal nerves of a dog when he accidentally pierced the dura mater.

The first planned spinal anaesthesia for surgery in man was administered by August Bier on $16^{\text {th }}$ August 1898. Heinrich Quincke of Kiel Germany described the technique of lumbar puncture in 1899. Spinal anaesthesia is one of the methods of anaesthesia for all procedures carried out on the lower half of the body. Spinal anaesthesia has the advantage of quicker onset of action as compared to epidural block and is technically easier. Neuraxial blocks not only reduce the incidence of deep venous thrombosis, pulmonary embolism, cardiac complications, bleeding, transfusion requirements and respiratory depression but also provide effective postoperative analgesia (Kleinman W et al 2006). ${ }^{4}$

Disadvantages of spinal anaesthesia include shorter duration of block and lack of top-up facilities unless a catheter is in and post dural-puncture headache (Kleinman $\mathrm{W}$ et al 
2006).4 Moreover geriatric patients have particularly high incidence of hypotension during spinal anaesthesia (Bruce, Bend David et al 2000). ${ }^{5}$

Presently, a vast choice of local anaesthetics is available. However, their toxicity issues have blemished the history of local anaesthesia since its inception. With a resurgence of interest in regional anaesthesia in the 1960s, the need for a longer acting local anaesthetic agent became apparent.

The drugs that have been used since past for this purpose are lidocaine, tetracaine and bupivacaine.

Lidocaine has been a popular anaesthetic agent for spinal anaesthesia. It was the first drug of the amino amide type to be introduced to clinical practice. 5\% lignocaine with $7.5 \%$ glucose was widely used for spinal anaesthesia of 30-60 minutes duration (Covino B G et al, 1986). ${ }^{6}$ However, several studies have questioned the use of lidocaine for spinal anaesthesia because of the frequency of transient neurological symptoms (Keld D B, Hein L et al 2000). ${ }^{7}$ These observations generated interest in an alternative local anaesthetic solution.

Bupivacaine, an amino amide compound was synthesised and introduced into the clinical practice in 1963, and it proved to be a very effective long-acting local anaesthetic agent. Bupivacaine is available as a racemic mixture of its enantiomers, dextrobupivacaine and levobupivacaine. In 1979, Albright drew attention bupivacaine and etidocaine; in case they gained accidental intravascular access. However, studies in animals indicate that bupivacaine, when injected intravascularly, induces a dose and rate dependent depression of drug elimination, resulting in re-entrant arrhythmias and cardiac depression, sometimes culminating in cardiac arrest (Clarkson C W et al 1985). ${ }^{8}$ These shortcomings of this otherwise novel local anaesthetic resulted in the development of more newer anaesthetic agent levobupivacaine. Till recently bupivacaine $0.5 \%$ heavy was the only drug used for spinal anaesthesia after the discontinuation of lidocaine via intrathecal use.

Levobupivacaine, the pure $S(-)$ enantiomer of racemic bupivacaine, is a newer long-acting local anaesthetic that has recently been introduced in the clinical routine. Because of its significantly decreased cardiovascular and central nervous system toxicity (Haung Y F et al 1998) ${ }^{9}$ as studied by various investigators, levobupivacaine seems to be an attractive alternative to bupivacaine. Numerous preclinical and clinical studies have compared levobupivacaine with bupivacaine and in most of the studies there is evidence that levobupivacaine is less toxic than bupivacaine (Stefania Leone et al 2008). ${ }^{10}$ The reversibility of levobupivacaine-induced cardiotoxicity has also been assessed. Some data point to an advantage of levobupivacaine over bupivacaine. Clinical studies have been conducted using surrogate markers of both cardiac and CNS toxicity. In these studies, levobupivacaine or bupivacaine was given by intravascular injection to healthy volunteers. Levobupivacaine was found to cause smaller changes in indices of cardiac contractility and the QTc interval of the electrocardiogram and also to have less depressant effect on the electroencephalogram (Gristwood R W et al 2002). ${ }^{11}$

Both LEVO-ANAWIN (Levobupivacaine solution) \& ANAWIN (Bupivacaine hydrochloride) are preservative free solution, $0.5 \%$ in concentration each, $10 \mathrm{~mL}$ of ampoule \& 20 $\mathrm{mL}$ ampoule respectively, Made in India by Neon Laboratories Limited.

\section{MATERIALS AND METHODS}

After obtaining informed written consent and the approval by the Ethics Committee, 100 patients aged 25-75 years, ASA I-III physical status, scheduled for lower abdominal \& lower limb surgery with spinal anaesthesia, were enrolled into the study done in Department of Anaesthesiology and Intensive Care Acharya Shri Chander College Of Medical Sciences And Hospital, Sidhra, Jammu, J\&K over a period of two years from December 2013-December 2015. All the different types of surgical procedures are summarised in table 4 . The patients affected by coagulation disturbances, neuromuscular diseases, ischaemic heart disease, spine deformity and hypersensitivity to amide local anaesthetics were excluded from the study.

After obtaining informed and written consent from the patients, complete pre-anaesthetic checkup was done a day before surgery. Each patient was subjected to complete general physical and systemic examination and detailed history was taken. VAS (Visual Analogue Scale) consisting of $10 \mathrm{~cm}$ line with $0=$ no pain and $10 \mathrm{~cm}=$ maximum imaginable pain, were explained to patient at preoperative visit. Baseline values of heart rate, noninvasive blood pressure were recorded. Basic demographic characteristics like age, sex, weight and height were noted.

All relevant investigations were done and the patient was kept fasting overnight. Tablet pantoprazole $40 \mathrm{mg}$ and tablet midazolam $7.5 \mathrm{mg}$ were advised at the bedtime on the night before surgery.

Two homogeneous groups containing 100 patients each were obtained by a randomisation table. On arrival in the anaesthetic room, an 18-gauge intravenous cannula was inserted and a $20 \mathrm{~mL} / \mathrm{kg}$ Ringer's solution was infused. Before starting anaesthesia, all patients were pre-medicated with IV ondansetron $0.1 \mathrm{mg} / \mathrm{kg}$ body weight and Inj. pantoprazole 40 mg.

The non-invasive monitor was attached to the patient and baseline vitals were noted. The patient was placed in sitting position. Under all aseptic precautions after painting the area and draping the back, skin overlying L3-L4 interspace was infiltrated with $2 \mathrm{~mL}$ of $2 \%$ Xylocaine. A $25-\mathrm{G}$ Quincke spinal needle was inserted at L3-L4 interspace. Correct needle placement was identified by free flow of cerebrospinal fluid. Anaesthesia was obtained by $0.5 \%$ glucose-free levobupivacaine $2.5 \mathrm{~mL}$ (Group L) or $0.5 \%$ isobaric bupivacaine $2.5 \mathrm{~mL}$ (Group B).

Sensory and motor blocks were assessed by the pinprick test Modified Bromage scale $(0=$ no paralysis, $1=$ inability to raise extended legs, $2=$ inability to flex the knee, $3=$ inability to flex the ankle).

Duration of motor blockade was recorded from the onset of grade 3 up to the regression of grade 0 block.

Haemodynamic variables such as systolic arterial pressure, diastolic arterial pressure and heart rate were recorded immediately after the injection, at $5 \mathrm{~min}$., $10 \mathrm{~min} ., 15$ min., $30 \mathrm{~min}$., $45 \mathrm{~min}$., $60 \mathrm{~min}$. and at the end of the procedure. Hypotension was taken as a fall in baseline systolic arterial pressure by $20 \%$. Hypotension was then treated with bolus doses of intravenous mephentermine $6 \mathrm{mg}$. Bradycardia was taken as heart rate less than 50 beats per minute. Bolus doses of intravenous atropine $0.3 \mathrm{mg}$ were injected to treat the episodes of bradycardia. 


\begin{tabular}{|c|c|c|c|c|c|c|c|c|c|}
\hline Heart Rate & \multicolumn{4}{|c|}{ Bupivacaine Group } & \multicolumn{4}{c|}{ Levobupivacaine Group } & p- \\
\hline & Min & Max & Mean & SD & Min & Max & Mean & SD & Value \\
\hline Baseline & 55 & 110 & 79.82 & 12.26 & 59 & 140 & 81.38 & 13.70 & 0.55 \\
\hline $\begin{array}{c}\text { Immediately After } \\
\text { Injection }\end{array}$ & 58 & 118 & 82.06 & 11.89 & 64 & 144 & 83.82 & 14.28 & 0.51 \\
\hline 5 Minutes & 63 & 122 & 82.96 & 11.88 & 60 & 141 & 83.54 & 13.76 & 0.82 \\
\hline 10 Minutes & 65 & 125 & 84.06 & 11.73 & 62 & 138 & 82.18 & 12.80 & 0.45 \\
\hline 15 Minutes & 66 & 116 & 84.10 & 10.50 & 62 & 122 & 81.22 & 11.30 & 0.19 \\
\hline 30 Minutes & 65 & 120 & 84.06 & 10.30 & 62 & 118 & 80.28 & 11.16 & 0.08 \\
\hline 45 Minutes & 67 & 98 & 82.40 & 7.99 & 67 & 106 & 80.84 & 7.86 & 0.33 \\
\hline 60 Minutes & 60 & 110 & 83.20 & 11.71 & 62 & 105 & 83.79 & 10.45 & 0.79 \\
\hline At the endof Procedure & 64 & 107 & 83.45 & 9.35 & 64 & 103 & 82.73 & 9.98 & 0.71 \\
\hline
\end{tabular}

This table shows the comparison of heart rate (beats/minute) between the two groups at baseline, immediately after injection of the drug, 5 minutes, 10 minutes, 15 minutes, 30 minutes 45 minutes, 60 minutes and at the end of procedure. The difference observed was statistically insignificant ( $\mathrm{p}$-value $>0.05$ ).

\begin{tabular}{|c|c|c|c|c|c|c|c|c|c|}
\hline Systolic Blood Pressure & \multicolumn{4}{|c|}{ Bupivacaine } & \multicolumn{4}{c|}{$\begin{array}{c}\text { Levobupivacaine } \\
\text { Group }\end{array}$} & \multirow{2}{*}{ p-Value } \\
\hline & Min. & Max. & Mean & SD & Min & Max & Mean & SD & \\
\hline Baseline & 108 & 145 & 130.34 & 8.94 & 106 & 144 & 127.18 & 7.96 & 0.07 \\
\hline Immediately After Injection & 105 & 145 & 129.62 & 9.48 & 100 & 144 & 127.60 & 8.13 & 0.25 \\
\hline 5 Minutes & 100 & 143 & 126.74 & 8.99 & 109 & 139 & 125.92 & 6.39 & 0.60 \\
\hline 10 Minutes & 104 & 142 & 124.36 & 8.98 & 107 & 135 & 123.88 & 6.82 & 0.76 \\
\hline 15 Minutes & 102 & 135 & 122.12 & 9.02 & 101 & 134 & 121.90 & 7.24 & 0.89 \\
\hline 30 Minutes & 100 & 138 & 120.38 & 8.98 & 104 & 132 & 120.44 & 6.95 & 0.97 \\
\hline 45 Minutes & 104 & 134 & 118.56 & 7.62 & 100 & 132 & 120.70 & 7.51 & 0.16 \\
\hline 60 Minutes & 100 & 135 & 117.92 & 6.71 & 90 & 135 & 120.10 & 8.05 & 0.15 \\
\hline At the End of Procedure & \multicolumn{1}{|c|}{109} & 128 & 118.06 & 4.87 & 101 & 128 & 119.16 & 6.82 & 0.11 \\
\hline Table 2: Comparison of Systolic Blood Pressure (mmHg) between Bupivacaine Group and Levobupivacaine Group \\
\hline
\end{tabular}

This table shows the comparison of Systolic Blood Pressure ( $\mathrm{mmHg}$ ) between the two groups at baseline, immediately after injection, 5 minutes, 10 minutes, 15 minutes, 30 minutes, 45 minutes, 60 minutes \& at the end of procedure.

The difference observed was statistically insignificant ( $\mathrm{p}$-value $>0.05$ ).

\begin{tabular}{|c|c|c|c|c|c|c|c|c|c|}
\hline \multirow[t]{2}{*}{ Diastolic Blood Pressure } & \multicolumn{4}{|c|}{ Bupivacaine Group } & \multicolumn{4}{|c|}{ Levobupivacaine Group } & \multirow{2}{*}{ p-value } \\
\hline & Min. & Max. & Mean & SD & Min. & Max. & Mean & SD & \\
\hline Baseline & 56 & 105 & 81.48 & 10.82 & 60 & 100 & 81.54 & 8.94 & 0.98 \\
\hline Immediately after Injection & 59 & 110 & 81.48 & 10.61 & 58 & 101 & 81.78 & 8.04 & 0.87 \\
\hline 5 Minutes & 55 & 99 & 77.32 & 9.59 & 62 & 94 & 79.88 & 7.90 & 0.14 \\
\hline 10 Minutes & 58 & 95 & 74.98 & 9.16 & 55 & 92 & 77.70 & 8.10 & 0.12 \\
\hline 15 Minutes & 55 & 94 & 75.12 & 7.76 & 54 & 90 & 76.66 & 7.58 & 0.32 \\
\hline 30 Minutes & 58 & 89 & 73.94 & 7.31 & 60 & 89 & 75.62 & 6.53 & 0.23 \\
\hline 45 Minutes & 60 & 84 & 73.30 & 6.10 & 61 & 87 & 74.86 & 6.55 & 0.22 \\
\hline 60 Minutes & 50 & 87 & 72.54 & 6.64 & 58 & 89 & 74.08 & 6.88 & 0.26 \\
\hline $\begin{array}{c}\text { At the } \\
\text { End of Procedure }\end{array}$ & 55 & 90 & 71.68 & 7.05 & 57 & 86 & 73.32 & 6.92 & 0.24 \\
\hline
\end{tabular}

Table 3: Comparison of Diastolic Blood Pressure ( $\mathrm{mmHg}$ ) between Bupivacaine Group and Levobupivacaine Group

This table shows the comparison of diastolic Blood Pressure (mmHg) between the two groups at baseline, immediately after injection, 5 minutes, 10 minutes, 15 minutes, 30 minutes, 45 minutes, 60 minutes \& at the end of procedure.

The difference observed was statistically insignificant $(\mathrm{p}$ value $>0.05$ )

Patients were monitored for 24 hours for dizziness, postoperative nausea and vomiting. Postoperative analgesia was evaluated using a standard $10 \mathrm{~cm}$ linear visual analogue scale (VAS) with 0 corresponding to no pain and 10 to the worst pain possible. Patients with a pain score of more than 3 on VAS were given rescue analgesia in the form of diclofenac sodium $50 \mathrm{mg}(2 \mathrm{~mL})$ intramuscularly. Duration of analgesia was recorded from its onset up to the time when pain was first reported.

Statistical analysis of the data was done using ANOVA and students t-test for difference of means (paired samples t-test). For quantitative analysis of nominal data, Chi-square test $\left(\chi^{2}\right.$-test $)$ was used. These tests were two sided and were referenced for $\mathrm{p}$-values for their significance. Any p-value less than 0.05 (i.e. $P<0.05$ ) was taken to be statistically significant. The analysis of the data was performed on statistical package for social sciences (SPSS version 16.0), Chicago, U.S.A. for windows. 
RESULTS

\begin{tabular}{|c|c|c|c|c|c|}
\hline & \multicolumn{2}{|c|}{$\begin{array}{c}\text { Bupivacaine } \\
\text { Group }\end{array}$} & \multicolumn{2}{|c|}{$\begin{array}{c}\text { Levobupivacaine } \\
\text { Group }\end{array}$} & \multirow{2}{*}{$\begin{array}{c}\text { p- } \\
\text { value }\end{array}$} \\
\hline & $\mathbf{N}$ & $\%$ & $\mathbf{N}$ & $\%$ & \\
\hline $\begin{array}{l}\text { Abscess } \\
\text { Drainage }\end{array}$ & 1 & 2 & 2 & 4 & \multirow{9}{*}{0.985} \\
\hline $\begin{array}{l}\text { Contracture } \\
\text { Release }\end{array}$ & 2 & 4 & 2 & 4 & \\
\hline Debridement & 6 & 12 & 4 & 8 & \\
\hline STSG & 3 & 6 & 5 & 10 & \\
\hline OIU & 5 & 10 & 6 & 12 & \\
\hline TURBT & 14 & 28 & 12 & 24 & \\
\hline TURP & 10 & 20 & 11 & 22 & \\
\hline $\begin{array}{l}\text { Wide Local } \\
\text { Excision }\end{array}$ & 2 & 4 & 1 & 2 & \\
\hline Orchidectomy & 7 & 14 & 7 & 14 & \\
\hline $\begin{array}{l}\text { Table 4: } C \\
\text { between } B\end{array}$ & par & $\begin{array}{l}\text { of } S \\
\text { Gro } \\
\text { Gro }\end{array}$ & ical & are. & \\
\hline
\end{tabular}

This table shows the comparison of surgical procedures done between the two groups. The difference observed was statistically insignificant ( $\mathrm{p}$-value $>0.05$ ).

100 patients were enrolled in the present study and randomised into the levobupivacaine group $(n=50)$ and the bupivacaine group $(n=50)$. There were no significant differences between the levobupivacaine and bupivacaine groups for demographic data, baseline haemodynamic parameters, ASA classification as shown in table 2. There were no significant differences between the two groups in the quality of sensory and motor block as shown in table 3 . The peak block height of the levobupivacaine group was T6, in the bupivacaine group was T6 and average in both groups were T9. No statistically significant difference was seen in the onset of sensory, motor blockade and the duration of regression of grade 3 to grade 0 blockade.

For assessment of pain with VNPS at the start of the operation when 0 is no pain and 10 is the worst imaginable pain. There were rated VPNS scores, with 0 at the time of the operation started in both groups. None of the 100 patients required supplement analgesics during the operative procedure.

With regard to intraoperative adverse events, hypotension was reported in 6 of 50 cases (12\%) in the levobupivacaine group compared to 5 of 50 cases $(10 \%)$ in the bupivacaine group ( $\mathrm{p}>0.05)$.

\begin{tabular}{|c|c|c|c|}
\hline $\begin{array}{c}\text { No. of } \\
\text { Parameters }\end{array}$ & Group B & Group L & p-value \\
\hline Age (y) & $48.72 \pm(11.77)$ & $44.54 \pm(12.30)$ & $0.09 \pm(\mathrm{NS})$ \\
\hline Weight (kg) & $60.72 \pm(7.95)$ & $60.88 \pm(7.79)$ & $0.92 \pm(\mathrm{NS})$ \\
\hline $\mathrm{M} / \mathrm{F}$ & $\begin{array}{c}40 / 10 \\
(80 \% / 20 \%)\end{array}$ & $\begin{array}{c}40 / 10 \\
(80 \% / 20 \%)\end{array}$ & $1.00 \pm(\mathrm{NS})$ \\
\hline $\begin{array}{c}\text { ASA Physical } \\
\text { Status }\end{array}$ & $\begin{array}{c}39 / 11 \pm \\
(785 / 22 \%)\end{array}$ & $\begin{array}{c}38 / 12 \pm \\
(76 \% / 24 \%)\end{array}$ & $0.50 \pm(\mathrm{NS})$ \\
\hline $\begin{array}{c}\text { HR (Beats/ } \\
\text { minute) }\end{array}$ & $\begin{array}{c}79.82 \pm \\
(12.26)\end{array}$ & $\begin{array}{c}81.38 \pm \\
(13.70)\end{array}$ & $0.55 \pm(\mathrm{NS})$ \\
\hline $\begin{array}{c}\text { Systolic BP } \\
\text { (mmHg) }\end{array}$ & $\begin{array}{c}130.34 \pm \\
(8.94)\end{array}$ & $\begin{array}{c}127.18 \pm \\
(7.96)\end{array}$ & $0.07 \pm(\mathrm{NS})$ \\
\hline $\begin{array}{c}\text { Diastolic BP } \\
\text { (mmHg) }\end{array}$ & $\begin{array}{c}81.48 \pm \\
(10.82)\end{array}$ & $\begin{array}{c}81.54 \pm \\
(8.94)\end{array}$ & $0.98 \pm(\mathrm{NS})$ \\
\hline \multicolumn{4}{|c|}{ Table 5: Demographic Data and Baseline } \\
Characteristics (Mean values \pm SD) \\
\hline \multicolumn{4}{|c}{} \\
\hline
\end{tabular}

\begin{tabular}{|c|c|c|c|}
\hline & \begin{tabular}{|c|} 
Levobupivacaine \\
$(n=50)$
\end{tabular} & $\begin{array}{c}\text { Bupivacaine } \\
(n=50)\end{array}$ & $\begin{array}{c}\text { p- } \\
\text { value }\end{array}$ \\
\hline $\begin{array}{l}\text { Time for Onset } \\
\text { of Highest } \\
\text { Sensory Block } \\
\text { (T10) (min.) }\end{array}$ & $\begin{array}{l}12.54 \pm \\
(3.24)\end{array}$ & $\begin{array}{l}11.60 \pm \\
(2.94)\end{array}$ & $\begin{array}{l}0.13 \pm \\
\text { (NS) }\end{array}$ \\
\hline $\begin{array}{l}\text { Time for Onset } \\
\text { of Grade } \\
3 \text { Motor } \\
\text { Block (min.) }\end{array}$ & $\begin{array}{l}7.30 \pm \\
(2.83)\end{array}$ & $\begin{array}{l}6.80 \pm \\
(2.61)\end{array}$ & $\begin{array}{l}0.36 \pm \\
\text { (NS) }\end{array}$ \\
\hline $\begin{array}{l}\text { Highest Level of } \\
\text { Sensory Block }\end{array}$ & T6 & T6 & 0.98 \\
\hline $\begin{array}{l}\text { Time to S } 2 \\
\text { Regression of } \\
\text { Sensory } \\
\text { Block (min.) }\end{array}$ & $\begin{array}{l}242.18 \pm \\
(34.51)\end{array}$ & $\begin{array}{c}245.42 \pm \\
(34.48)\end{array}$ & $\begin{array}{c}0.64 \pm \\
(N S)\end{array}$ \\
\hline $\begin{array}{l}\text { Time for } \\
\text { Regression of } \\
\text { Motor Block } \\
\text { from Grade } 3 \text { to } \\
\text { Grade } 0 \text { (min.) }\end{array}$ & $\begin{array}{l}184.04 \pm \\
(21.70)\end{array}$ & $\begin{array}{l}189.46 \pm \\
(21.58)\end{array}$ & $\begin{array}{l}0.21 \pm \\
\text { (NS) }\end{array}$ \\
\hline $\begin{array}{c}\text { Duration of } \\
\text { Analgesia }\end{array}$ & $\begin{array}{l}259.18 \pm \\
(33.64)\end{array}$ & $\begin{array}{l}262.80 \pm \\
(33.49)\end{array}$ & $\begin{array}{l}0.59 \pm \\
\text { (NS) }\end{array}$ \\
\hline
\end{tabular}

\begin{tabular}{|c|c|c|c|}
\hline & $\begin{array}{c}\text { Levobupivacaine } \\
(\mathbf{n = 5 0 )}\end{array}$ & $\begin{array}{c}\text { Bupivacaine } \\
(\mathbf{n = 5 0 )}\end{array}$ & $\begin{array}{c}\text { p- } \\
\text { Value }\end{array}$ \\
\hline Hypotension & $6(12 \%)$ & $5(10 \%)$ & $0.750(\mathrm{NS})$ \\
\hline Bradycardia & $3(6 \%)$ & $2(4 \%)$ & $0.648(\mathrm{NS})$ \\
\hline $\begin{array}{c}\text { Nausea/ } \\
\text { Vomiting }\end{array}$ & $3(6 \%)$ & $2(4 \%)$ & $0.648(\mathrm{NS})$ \\
\hline $\begin{array}{c}\text { Respiratory } \\
\text { Depression }\end{array}$ & $0(0 \%)$ & $0(0 \%)$ & $1.000(\mathrm{NS})$ \\
\hline Shivering & $2(4 \%)$ & $1(2 \%)$ & $0.560(\mathrm{NS})$ \\
\hline \multicolumn{3}{|c|}{$\begin{array}{r}\text { Table 7: Intraoperative Adverse Events (Values } \\
\text { shown as mean/SD and frequency/\%) }\end{array}$} \\
\hline
\end{tabular}

\section{DISCUSSION}

Levobupivacaine has gained popularity as alternative to bupivacaine because of its equipotency with lower cardiovascular and central nervous system side effects. It has very similar pharmacokinetic properties to those of racemic bupivacaine, several studies supported the notion that its faster protein binding rate reflects a decreased degree of toxicity. Accidental intravenous injection of bupivacaine during attempted epidural anaesthesia in pregnant women caused cardiac arrest. The same event of levobupivacaine caused only transient agitation and the patient recovered fully. Due to its long duration of action, bupivacaine is one of the commonest local anaesthetics used. However, profound myocardial depression and even cardiac arrest can occur after accidental intravascular injection. Resuscitation from bupivacaine induced cardiovascular collapse has been found to be difficult and may be unsuccessful. Levobupivacaine administered via epidural has the advantage of less cardiotoxicity if accidental intravascular injections occur. Since the dose of bupivacaine used in spinal anaesthesia is small, the issue of cardiotoxicity is less important. Nevertheless, investigation of the clinical effects of intrathecal levobupivacaine is important; because there is the possibility of accidental intrathecal injection during epidural anaesthesia and the event of sudden cardiovascular collapse, cardiac arrest 
during spinal anaesthesia with racemic bupivacaine were also reported rate as 1:1000.

Our decision to use isobaric levobupivacaine was based on fact that compared to heavy solutions, use of isobaric local anaesthetic solutions results not only in predictable cephalic spread, but also decreases the toxicity if in advertent intravascular injection of drug occurs. Besides, by using both the isobaric solution, the bias of baricity was eliminated in our study. The present study was undertaken to compare the effects of intrathecal bupivacaine and levobupivacaine in patients undergoing lower abdominal and lower limb surgeries with regard to onset of sensory and motor block, total duration of sensory and motor block, S2 regression, haemodynamic alternations, intraoperative and postoperative complication.

In a study done by Ozgun Cuvas et al (2010) ${ }^{12}$ to compare the characteristics of spinal block produced by $0.5 \%$ levobupivacaine with \& without fentanyl in urological surgery, they found no statistical significant difference in heart rates between the two groups. There were no significant differences in potency and side effects. Christian Glaser et al (2002). ${ }^{13}$ performed a study comparing an isobaric solution of $0.5 \%$ levobupivacaine and $0.5 \%$ racemic bupivacaine $3.5 \mathrm{~mL}$ for spinal anaesthesia for elective hip replacement. They found similar clinical effects, including sensory and motor block. Alley E et al (2002) ${ }^{14}$ conducted a randomised, double blind, cross over study in healthy volunteers to compare $0.25 \%$ hyperbaric levobupivacaine and racemic bupivacaine for spinal anaesthesia. Lee YY et al (2003), ${ }^{15}$ who compared the clinical efficacy and motor block of $0.5 \%$ levobupivacaine with $0.5 \%$ racemic bupivacaine in spinal anaesthesia for urological surgeries. There was no statistical significant difference in heart rates between the two groups. Levobupivacaine and racemic bupivacaine showed equivalent efficacy in terms of sensory and motor block.

The present study demonstrated that $0.5 \%$ isobaric levobupivacaine, the pure $\mathrm{S}(-)$ enantiomer of racemic bupivacaine, is as effective as $0.5 \%$ isobaric bupivacaine for spinal anaesthesia in lower abdominal and lower limb surgeries that requires a sensory block of at least T10. Onset time and duration of the sensory and motor block, peak block height and recovery time of the sensory and motor and haemodynamics are similar to those obtained with isobaric bupivacaine.

To summarise, the results of the present study indicate that $2.5 \mathrm{~mL}$ of $0.5 \%$ isobaric levobupivacaine and $0.5 \%$ isobaric bupivacaine show equally effective potencies for spinal anaesthesia, both regards to the haemodynamic variables, onset time and duration of sensory \& motor blockade.

Based on these data, we conclude that levobupivacaine although has no added advantage over bupivacaine, but having lesser cardiac and CNS effects after accidental intravascular injection is an interesting alternative to bupivacaine for spinal anaesthesia in lower abdominal and lower limb surgeries.

\section{REFERENCES}

1. Farquhar-Smith W. Anatomy, physiology and pharmacology of pain. Anaesthesia and Intensive Care Medicine 2008;9(1):3-7.

2. Lubenow TR, Anthony D, Robert RL. Management of postoperative pain. Clinical Anaesthesia. $5^{\text {th }}$ edn. Philadelphia: Lippincott Williams \& Wilkins 2006:1405.

3. Bacon DR, Wilkinson DJ. Great moments in the history of anesthesiology. Chapter 1. Wylie \& Churchill Davidson's A practice of anaesthesia. $7^{\text {th }}$ edn. London: Arnold 2003.

4. Kleinman W, Mikhail M. Regional anaesthesia and pain management. Clinical anaesthesiology. $4^{\text {th }}$ edn. New York: McGraw-Hill 2006:270.

5. Ben-David B, Frankel R, Arzumonov T, et al. Mini dose bupivacaine-fentanyl anesthesia for surgical repair of hip fracture in aged. Anaesthesiology 2000;92(1):6-10.

6. Covino BG. Pharmacology of local anaesthetic agent. British Journal of Anaesthesia 1986;58(7):701-16.

7. Keld DB, Hein L, Dalgaard $M$, et al. The incidence of transient neurologic symptoms after spinal anesthesia in patients undergoing surgery in supine position. Hyperbaric lidocaine $5 \%$ versus hyperbaric bupivacaine $0.5 \%$. Acta Anaesthesiologica Scandinavica 2000;44(3):285-90.

8. Clarkson CW, Hondeghem LM. Mechanism for bupivacaine depression of cardiac conduction: fast block of sodium channels during the action potential with slow recovery from block during diastole. Anaesthesiology 1985;62(4):396-405.

9. Huang YF, Pryor ME, Mather LE, et al. Cardiovascular and central nervous system effects of intravenous levobupivacaine and bupivacaine in sheep. Anesthesia Analgesia 1998;86(4):797-804.

10. Leone S, Di Cianni S, Casati A, et al. Pharmacology, toxicology, and clinical use of new long acting local anesthetic ropivacaine and levobupivacaine. Acta Biomed 2008;79(2):92-105.

11. Gristwood RW. Cardiac and CNS toxicity of levobupivacaine: strengths of evidence for advantage over bupivacaine. Drug Safety 2002;25(3):153-63.

12. Glaser C, Marhofer P, Zimpfer G, et al. Levobupivacaine versus racemic bupivacaine for spinal anesthesia. Anaesthesia Analgesia 2002;94(1):194-8.

13. Lee YY, Muchhal K, Chan CK. Levobupivacaine versus racemic bupivacaine in spinal anaesthesia for urological surgeries. Anaesthesia \& Intensive Care 2003;31(6): 637-41.

14. Cuvas O, Basar H, Yeygel A, et al. Spinal anesthesia for transurethral resection operations: levobupivacaine with or without fentanyl. Middle East Journal of Anaesthesiology 2010;20(4):547-52.

15. Alley EA, Kopacz DJ, McDonald SB, et al. Hyperbaric spinal levobupivacaine: a comparison to racemic bupivacaine in volunteers. Anesthesia \& Analgesia 2002;94(1):188-93. 